\title{
Female hormonal exposures and neuromyelitis optica symptom onset in a multicenter study
}

\section{OPEN}

Riley Bove, MD, MSc

Liene Elsone, MD

Enrique Alvarez, MD,

$\mathrm{PhD}$

Nadja Borisow, MD

Melissa M. Cortez, DO

Farrah J. Mateen, MD,

$\mathrm{PhD}$

Maureen A. Mealy, RN,

BSN, MSCN

Kerry Mutch, RGN, MSc

Sean Tobyne, MA

Klemens Ruprecht, MD

Guy Buckle, MD

Michael Levy, MD, PhD

Dean M. Wingerchuk, MD

Friedemann Paul, MD

Anne H. Cross, MD

Brian Weinshenker, MD

Anu Jacob, MD, FRCP

Eric C. Klawiter, MD, MSc

Tanuja Chitnis, MD

Correspondence to

Dr. Chitnis:

tchitnis@bwh.harvard.edu

\section{ABSTRACT}

Objective: To study the association between hormonal exposures and disease onset in a cohort of women with neuromyelitis optica spectrum disorder (NMOSD).

Methods: Reproductive history and hormone use were assessed using a standardized reproductive survey administered to women with NMOSD (82\% aquaporin- 4 antibody positive) at 8 clinical centers. Using multivariable regression, we examined the association between reproductive exposures and age at first symptom onset (FS).

Results: Among 217 respondents, the mean age at menarche was 12.8 years (SD 1.7). The mean number of pregnancies was 2.1 (SD 1.6), including 0.3 (SD 0.7) occurring after onset of NMOSD symptoms. In the 117 participants who were postmenopausal at the time of the questionnaire, $70 \%$ reported natural menopause (mean age: 48.9 years [SD 3.9]); fewer than 30\% reported systemic hormone therapy (HT) use. Mean FS age was 40.1 years (SD 14.2). Ever-use of systemic hormonal contraceptives $(\mathrm{HC}$ ) was marginally associated with earlier FS (39 vs 43 years, $\mathrm{p}=0.05$ ). Because $\mathrm{HC}$ use may decrease parity, when we included both variables in the model, the association between $\mathrm{HC}$ use and FS age became more significant (estimate $=2.7, \mathrm{p}=$ 0.007). Among postmenopausal participants, 24\% reported NMOSD onset within 2 years of (before or after) menopause. Among these participants, there was no association between age at menopause or HT use and age at NMOSD onset.

Conclusions: Overall, age at NMOSD onset did not show a strong relationship with endogenous hormonal exposures. An earlier onset age did appear to be marginally associated with systemic $\mathrm{HC}$ exposure, an association that requires confirmation in future studies. Neurol Neuroimmunol Neuroinflamm 2017;4:e339; doi: 10.1212/NXI.0000000000000339

\section{GLOSSARY}

FS = first symptom onset; $\mathbf{H C}=$ hormonal contraceptives; $\mathbf{H T}=$ hormone therapy; $\mathbf{N M O}=$ neuromyelitis optica; NMOSD = neuromyelitis optica spectrum disorder.

Neuromyelitis optica (NMO) is a severe inflammatory neurologic disease, whose main clinical manifestations are simultaneous or successive episodes of optic neuritis and transverse myelitis. $\mathrm{NMO}$ is associated with serum immunoglobulin $\mathrm{G}$ antibodies to aquaporin-4, which are present in about $75 \%$ of patients with NMO. "NMO-spectrum disorders" (NMOSDs) is a unifying term to describe the clinical spectrum of NMO, including aquaporin- 4 antibody-positive patients with limited forms of the disease. The female-to-male ratio in NMOSD is up to 9:1, ${ }^{1,2}$ but the role of sex-specific hormones in disease pathogenesis has not been explored.

In MS, another CNS demyelinating disease with high female:male ratio (2-3:1 and possibly increasing ${ }^{3,4}$ ), earlier age at menarche is associated with earlier age at MS onset. Pregnancy reduces the risk of an MS relapse, ${ }^{5,6}$ and increasing parity is associated with lower risk of

From the Brigham and Women's Hospital (R.B., T.C.), Boston, MA; Harvard Medical School (R.B., F.J.M., E.C.K., T.C.), Boston, MA; The Walton Centre NHS Foundation Trust (L.E., K.M., A.J.), Liverpool, UK; Washington University School of Medicine (E.A., A.H.C.), St. Louis, MO; Charité-Universitätsmedizin Berlin (N.B., K.R., F.P.), Germany; University of Utah Imaging \& Neurosciences Center (M.M.C.), Salt Lake City; Massachusetts General Hospital (F.J.M., S.T., E.C.K.), Boston; Johns Hopkins Medical Institute (M.A.M., M.L.), Baltimore, MD; MS Institute at Shepherd Center (G.B.), Atlanta, GA; Mayo Clinic (B.W.), Rochester, MN; and Mayo Clinic (D.M.W.), Scottsdale, AZ.

Funding information and disclosures are provided at the end of the article. Go to Neurology.org/nn for full disclosure forms. The Article Processing Charge was paid by the authors.

This is an open access article distributed under the terms of the Creative Commons Attribution-NonCommercial-NoDerivatives License 4.0 (CC BY-NC-ND), which permits downloading and sharing the work provided it is properly cited. The work cannot be changed in any way or used commercially without permission from the journal. 
long-term disease progression. ${ }^{7}$ In NMOSD, the risk of relapses and of first disease onset is increased during the pregnancy and postpartum periods relative to baseline..$^{8-11}$

In this cohort study, we hypothesized that, as seen in MS, both exogenous and endogenous hormonal exposures are associated with age at NMOSD onset. First, we describe the reproductive exposures of an international multicenter cohort of women with NMOSD; second, we examine the association between these hormonal exposures and age at disease onset.

METHODS Setting. A standardized reproductive survey was conducted between June 2011 and May 2013 for women with NMOSD ( $82 \%$ antibody positive) at 8 clinical centers, who were identified by chart review. These centers were as follows: Walton Centre in Liverpool, England ( $\mathrm{n}=56$ ), Mayo Clinic-Rochester $(\mathrm{n}=39)$, Washington University in St. Louis $(\mathrm{n}=36)$, Charité Universitätsmedizin Berlin $(\mathrm{n}=26)$, Mayo Clinic-Scottsdale ( $\mathrm{n}=$ 25), Johns Hopkins University $(\mathrm{n}=19)$, and Massachusetts General Hospital/Brigham and Women's Hospital $(n=16)$.

Standard protocol approvals, registrations, and patient consents. Informed consent was obtained from all participants under institutional review board policies at each site.

Participants. A total of 217 women who met current published diagnostic criteria for NMOSD with or without aquaporin-4 antibodies $^{12}$ were enrolled consecutively, and all participants completed at least 1 component of the questionnaire.

Questionnaire. The reproductive survey included questions about menarche, pregnancies, menopause, and exogenous hormones. ${ }^{13}$ It was conducted using REDCap, a secure Health Insurance Portability and Accountability Act compliant web-based survey tool. This questionnaire had previously good concordance of selected variables against the medical record in women with MS. ${ }^{14}$ For this study, the following variables were examined:

1. Age at menarche.

2. Hormonal contraceptive (HC) use: Ever-use of HC was further divided by administration (oral, transdermal, IM) and duration (less than, vs at least, 12 months). The 12-month duration was selected because analyzing $\mathrm{HC}$ use over shorter timeframes might introduce more substantial recall bias. The formulation (estrogen, progestogen, or combined) or dosing of HC was not assessed.

3. Number of pregnancies, including lifetime and after NMOSD first symptom onset (FS).

4. Current reproductive status was categorized as cycling, perimenopausal (last menses in the 3-12 months prior to survey), or postmenopausal (no menses in the prior 12 months or loss of menses due to surgery). Type was categorized as (1) natural, or resulting from (2) surgical intervention (hysterectomy and/ or bilateral oophorectomy) or (3) chemotherapy or radiation. Menopausal Age was defined as last menstrual period beyond which no menses occurred for 1 year (natural) or surgery date, according to Stages of Reproductive Aging Workshop +10 guidelines. ${ }^{15}$

5. Menopausal hormone therapy (HT) use was categorized dichotomously for type (estrogen and/or progestogens vs other types [black cohosh, testosterone, etc]) and administration (systemic [patch + oral] vs local [gel, cream, and ring]), and for this analysis we included only systemic, homone-based HT.

Statistical analysis. Descriptive statistics were used to summarize demographic, clinical, and reproductive characteristics. To examine the association between reproductive exposures and reported age at FS, we used multivariable regressions. Data were analyzed using the SAS-based software program JMP, version 8.0.1 (SAS Institute, Cary, NC).

RESULTS Study population. The demographic and disease characteristics of the 217 respondents are provided in table 1. Mean FS age was 40.1 years (SD 14.2, median 39.8, and interquartile range 28.0-51.6). There was no relationship between FS age and $\mathrm{NMO}$ antibody positivity $\left(\chi^{2}, p=0.68\right)$. With respect to hormonal exposures, the mean age at menarche was 12.8 years (SD 1.7), and 61\% of women reported systemic oral $\mathrm{HC}$ use for at least 12-month duration. The median number of total pregnancies was 2 (SD 1.6) and occurring after NMOSD FS was 0 (SD 0.7). Thirteen percentage of respondents (26/193) reported delay in achieving pregnancy of 12 months or longer, and in the 11 in whom a reason for their infertility was identified, the causes were as follows: ovarian cysts $(\mathrm{n}=3)$, structural problems $(\mathrm{n}=3$, including 1 endometriosis), hormonal dysregulation $(\mathrm{n}=3)$, and male factors $(n=2)$. Twelve participants $(6 \%)$ reported receiving infertility treatment.

Among the 117 postmenopausal participants, 70\% $(\mathrm{n}=82)$ reported natural menopause (mean age: 48.9 years [SD 3.9]); only $25 \%(n=29)$ reported systemic HT use. Given prior reports that women with neurologic disabilities may access fewer components of general health promotion (such as cancer screening, ${ }^{16}$ or HT, which was often "standard of care" during the epoch corresponding to this cohort's menopausal transition ${ }^{17}$ ), we compared HT use in postmenopausal participants with FS occurring before vs after their final menstrual period. Women with FS after their menopause reported greater HT use $(37 \%)$ than women with FS prior to menopause $\left(16 \% ; \chi^{2}\right.$ test $=5.68$, $p=0.016)$. Association between reproductive exposures and age at disease onset is summarized in table 2:

Menarche. Ten participants (4.6\%) reported FS prior to age of 18,7 of whom reported FS within 2 years prior to $(n=2)$ or after $(n=5)$ menarche. There was no association between FS age and menarcheal age (linear regression, estimate $=0.91, p=0.12$ ).

HC use. Ever-use of systemic HC was associated with earlier FS (39.3 vs 43.4 years), but this was marginally significant (linear regression, estimate $=$ $2.1, p=0.05$; figure).

Parity. A later FS was also associated with a greater number of preceding pregnancies (estimate $=3.3$, $p<0.0001)$. Because participant age confounded 
Table 1 Demographic, clinical, and reproductive characteristics of 217 women with NMOSD from 8 participating clinical centers

\begin{tabular}{|c|c|c|c|}
\hline & Mean (SD) or $n(\%)$ & Range & n \\
\hline \multicolumn{4}{|l|}{ Demographic characteristics } \\
\hline Age survey, y & 49.4 (14.3) & $17-83$ & 217 \\
\hline Race & & & 217 \\
\hline Caucasian & $165(76)$ & & \\
\hline Black or African American & $36(17)$ & & \\
\hline Asian & $12(6)$ & & \\
\hline Other & 4 (2) & & \\
\hline Ethnicity & & & 198 \\
\hline Hispanic & $9(5)$ & & \\
\hline Marital status & & & 217 \\
\hline Married & $133(61)$ & & \\
\hline Single & $50(23)$ & & \\
\hline Divorced & $22(10)$ & & \\
\hline Widowed & $12(6)$ & & \\
\hline \multicolumn{4}{|l|}{ Disease characteristics } \\
\hline Age at first symptoms & 40.1 (14.2) & $10-76$ & 217 \\
\hline NMO antibody test & & & 214 \\
\hline Positive & $175(82)$ & & \\
\hline Negative & $36(17)$ & & \\
\hline Does not know & $3(1)$ & & \\
\hline \multicolumn{4}{|l|}{ Reproductive characteristics } \\
\hline Age at menarche & $12.8(1.7)$ & 9-23; IQR 12-14 & 214 \\
\hline Ever pregnant & & & 217 \\
\hline Yes & $172(79)$ & & \\
\hline No & $45(21)$ & & \\
\hline \multicolumn{4}{|l|}{ No. of pregnancies } \\
\hline Total & 2.1 (1.6); median: 2 & $0-6$ & 212 \\
\hline Prior to NMOSD first symptoms & 1.9 (1.6); median: 2 & $0-6$ & 210 \\
\hline After NMOSD first symptoms & 0.3 (0.7); median: 0 & $0-4$ & 210 \\
\hline Ever-use of systemic $\mathrm{HC}$ & & & 212 \\
\hline Yes & $148(70)$ & & \\
\hline No & $64(30)$ & & \\
\hline \multicolumn{4}{|l|}{ Systemic HC use } \\
\hline None & $64(30)$ & & 207 \\
\hline Oral, <12 mo & $13(6)$ & & \\
\hline Oral, $\geq 12 \mathrm{mo}$ & $127(61)$ & & \\
\hline Transdermal, IM & $3(1)$ & & \\
\hline Current reproductive status & & & 217 \\
\hline Cycling & $91(42)$ & & \\
\hline Perimenopausal & $9(4)$ & & \\
\hline Postmenopausal & $117(54)$ & & \\
\hline \multicolumn{4}{|l|}{ Postmenopausal only } \\
\hline Menopausal type & & & 117 \\
\hline Natural & $82(70)$ & & \\
\hline
\end{tabular}


Table 1 Continued

Mean (SD) or $\mathbf{n}(\%)$

Bilateral oophorectomy

Hysterectomy and/or unilateral oophorectomy

Chemotherapy

Radiation

Systemic HT use

None

Estrogen

Estrogen + progestin

Other or missing
18 (15)

Range

n

7 (6)

9 (8)

1 (1)

116

$81(70)$

25 (22)

4 (3)

6 (5)

Abbreviations: $\mathrm{HC}=$ hormonal contraceptive; $\mathrm{HT}=$ hormone therapy; IQR = interquartile range; $\mathrm{NMO}=$ neuromyelitis optica; NMOSD = neuromyelitis optica spectrum disorder.

the interpretation (i.e., parity increases with age), we categorized individuals according to FS age (before 30, 30-39, 40-49, and 50 years and older). When we included this categorical term in the linear regression model, the association between FS age and number of preceding pregnancies was not significant (linear regression, estimate $=0.30$, $p=0.16)$.

Because $\mathrm{HC}$ use might result in lower parity, we included both parity and $\mathrm{HC}$ use in a linear regression model, and the association between HC use and FS age became more significant (linear regression, estimate $=2.7, p=0.007)$; the number of preonset pregnancies remained significant (linear regression, estimate $=3.3, p<0.0001)$.
Menopause. Among the 106 women who were postmenopausal at the time of the survey and who provided a menopausal age, there was no relationship between age at menopause and FS age (linear regression, estimate $=0.30, p=0.10$ ). Among these women, 59 (56\%) reported FS after their final menstrual period and 25 (24\%) reported FS within 2 years of their final menstrual period ( $\mathrm{n}=18$ before and $\mathrm{n}=7$ after). In women with postmenopausal onset of FS, there was no relationship between systemic HT use and FS age (linear regression, estimate $=0.95, p=0.66$ ).

In sensitivity analyses, the significance of the findings reported was unchanged when we included race, ethnicity, and NMO antibody positivity as covariates in the models.

Table 2 Summary of results

\begin{tabular}{|c|c|c|}
\hline & Model & $\mathbf{N}$ \\
\hline \multicolumn{3}{|l|}{ All respondents } \\
\hline Menarcheal age & Linear regression & Estimate $=0.91, p=0.12$ \\
\hline \multirow[t]{2}{*}{ Parity } & Linear regression & Estimate $=3.3, p<0.0001^{a}$ \\
\hline & $\begin{array}{l}\text { Linear regression, adjusting for FS } \\
\text { age category }\end{array}$ & Estimate $=0.30, p=0.16$ \\
\hline Systemic $\mathrm{HC}$ use $^{\mathrm{c}}$ & Linear regression & $\begin{array}{l}\text { Estimate }=2.1, p=0.05^{a} \text { (never-users had later } \\
\text { FS than ever-users: } 43.4 \text { vs } 39.3 \text { y) }\end{array}$ \\
\hline Parity and $\mathrm{HC}$ use & $\begin{array}{l}\text { Linear regression, including both } \\
\text { parity and } \mathrm{HC} \text { use }\end{array}$ & $\begin{array}{l}\text { Estimate for parity }=3.3, p<0.0001^{a} \\
\text { estimate for } \mathrm{HC} \text { use }=2.7, p=0.007^{\mathrm{a}}\end{array}$ \\
\hline \multicolumn{3}{|c|}{$\begin{array}{l}\text { Postmenopausal respondents only } \\
(\mathrm{N}=106)\end{array}$} \\
\hline Age at menopause & Linear regression & Estimate $=0.30, p=0.10$ \\
\hline \multicolumn{3}{|c|}{$\begin{array}{l}\text { Participants with postmenopausal } \\
\text { onset only ( }=59)\end{array}$} \\
\hline Systemic HT use & Linear regression & Estimate $=0.95, p=0.66$ \\
\hline
\end{tabular}

Abbreviations: $\mathrm{FS}=$ first symptom onset; $\mathrm{HC}=$ hormonal contraceptive; $\mathrm{HT}=$ hormone therapy.

${ }^{\mathrm{b}}$ Before 30, 30-39, 40-49, and 50 years and older.

${ }^{\mathrm{c}}$ Categorized as never-use vs 12 months or more. 
Figure Age at NMOSD first symptom onset in women with and without prior exposure to systemic hormonal contraceptives

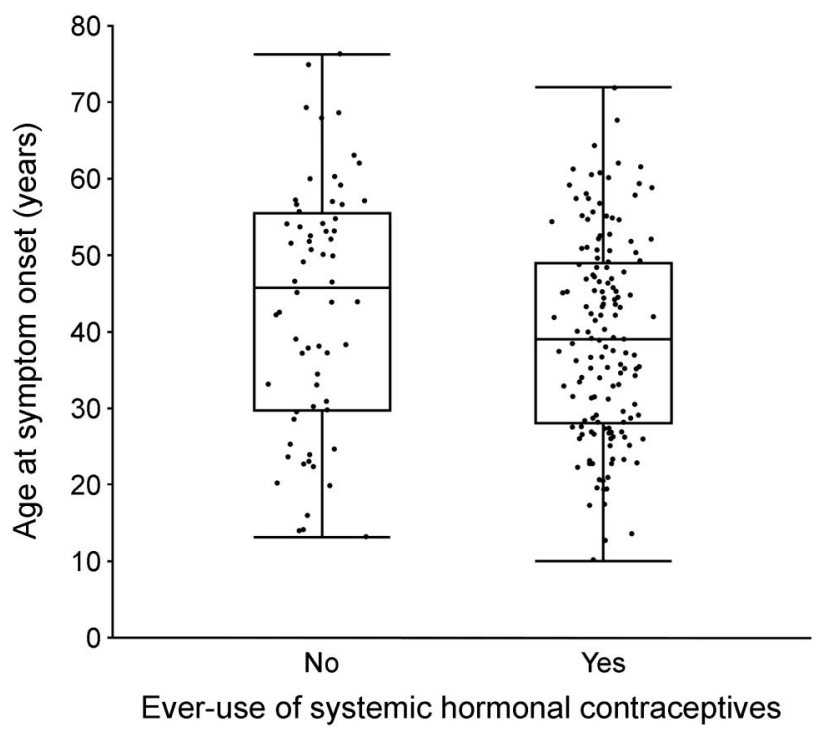

NMOSD $=$ neuromyelitis optica spectrum disorder.

DISCUSSION This study, conducted in a large international survey of women with NMOSD, represents a preliminary analysis of the relationship from NMOSD onset to hormonal factors beyond pregnancy.

With respect to endogenous exposures, unlike in MS, we saw no association between menarcheal age and NMOSD onset. ${ }^{18-21}$ As in other cohorts, 5\% of our participants reported FS before the age of $18 .^{2,22}$ The association between a greater number of preceding pregnancies and later NMOSD FS $(p<0.0001)$ was expected, as parity increases with age. Future studies should examine the association between age at first offspring's birth (not available in our cohort) and FS age. It is important that the number of pregnancies after disease onset was far outnumbered by those prior to disease onset. While this may partly reflect the older age of women at FS, it may also reflect reproductive choices relating to uncertainty of disease course, need for new medications that have uncertain effects on a fetus, and concerns about the future ability to care for a child, as has been reported in MS. ${ }^{23}$ Inclusion of NMO antibody positivity in the sensitivity analyses did not change the significance (or nonsignificance) of the relationship between endogenous hormonal exposures and FS age. In a separate manuscript, we describe the association between pregnancy and relapses in this cohort (Klawiter, personal communication). It is notable that $6 \%$ of the respondents reported use of fertility treatments. Larger case-control studies adjusting for participant age are needed to determine whether there is an association between NMOSD and infertility.

With respect to exogenous exposures, we observed a marginally significant association between ever-use of $\mathrm{HC}$ and earlier age at NMOSD onset. From a broader perspective, evidence for an association between HC and autoimmune diseases is mixed (including lower, ${ }^{24-26}$ neutral, ${ }^{27,28}$ and higher ${ }^{29}$ risk of MS) and likely is confounded by changing HC formulations across epochs. Furthermore, the confounding effect of delayed (or no) childbearing that is achieved through $\mathrm{HC}$ use has not been adequately assessed, nor has the effect of participant age on recall of $\mathrm{HC}$ use. Follow-up studies are required to confirm this association, and, if this is confirmed, to assess $\mathrm{HC}$ dosing effects and whether the association is causative.

Approximately, one-quarter of all participants reported a postmenopausal onset of FS, which contrasts with MS, where fewer than 10\% develop MS FS after the age of $50 .{ }^{30}$ The detection rate of serum aquaporin4 autoantibodies has been reported to increase in women relative to men particularly after the age of 50 , suggesting an effect of reproductive immunosenescence on NMOSD features. ${ }^{22}$ We observed no relationship between FS age and reported NMO antibody positivity.

The primary strengths of this multicenter study include an international design with a relatively large sample size, the use of specific diagnostic criteria for NMOSD, and the use of a standardized fairly comprehensive reproductive survey. Still, numbers were overall low, participants were mostly Caucasians from European and North American centers, possibly limiting generalizability of findings, occasionally data were missing, and reliance on patient-reported hormonal exposures may have introduced recall bias. In addition, we were not adequately powered to detect epochal factors potentially associated with both exogenous hormone use and NMOSD susceptibility or disease course, or to detect differences across clinical centers. We also identified further refinements needed to the reproductive survey (e.g., age at first birth and HC formulations).

While we selected age at NMOSD as our initial clinical measure of interest, further studies should evaluate the association between endogenous and exogenous hormonal exposures and other NMOSD characteristics of interest, including clinical severity and progression, and severity of inflammation on MRI.

Studies that include detailed hormonal analysis and immunopathogenetic measures are required to replicate these results and further elucidate the role of endogenous and exogenous hormonal exposures on this female predominant autoimmune disease, as well as important pathophysiologic implications.

\section{AUTHOR CONTRIBUTIONS}

Study concept and design: R.B., E.C.K., and T.C. Statistical analysis and interpretation of data: R.B. and F.J.M. Acquisition of data and interpretation of results: L.E., E.A., N.B., M.M.C., F.J.M., M.A.M., K.M., S.T., 
K.R., G.B., M.L., D.M.W., F.P., A.H.C., B.W., A.J., E.C.K., and T.C. Manuscript drafting and revising: R.B., L.E., E.A., N.B., M.M.C., F.J.M., M.A.M., K.M., S.T., K.R., G.B., M.L., D.M.W., F.P., A.H.C., B.W., A.J., E.C.K., and T.C.

\section{STUDY FUNDING}

This work was supported by the Guthy-Jackson Charitable Foundation. R.B. was supported by the National Multiple Sclerosis Society and the NIH (BIRCWH K12). K.R. and F.P. were supported by the German ministry of education and research (BMBF/KKNMS, Competence Network Multiple Sclerosis).

\section{DISCLOSURE}

R. Bove received research support from NIH, Brigham and Women's Hospital BWPO, and National MS Society-American Brain Foundation. L. Elsone received travel funding from TEVA Pharmaceuticals and European Charcot Foundation. E. Alvarez received research support from Biogen, Novartis, Acorda, Genentech, and Rocky Mountain MS Center. N. Borisow, M.M. Cortez, and F.J. Mateen report no disclosures. M.A. Mealy received speaker honoraria from Consortium of Multiple Sclerosis Centers. K. Mutch and S. Tobyne report no disclosures. K. Ruprecht served on the scientific advisory board for Sanofi-Aventis/Genzyme, Novartis, and Roche; received travel funding and/or speaker honoraria from Bayer Healthcare, Biogen Idec, Merck Serono, Sanofi-Aventis/Genzyme, Teva Pharmaceuticals, Novartis, and Guthy-Jackson Charitable Foundation; is an academic editor for PLoS One; receives publishing royalties from Elsevier; and received research support from Novartis and German Ministry of Education and Research. G. Buckle received travel funding and/or speaker honoraria from, consulted, and served on the speakers' bureau for Biogen Idec, EMD Serono, Genentech, Genzyme Sanofi, Mallinckrodt, Novartis, and Teva. M. Levy served on the scientific advisory board for Asterias, Chugai, and Alexion; served on the editorial board for Multiple Sclerosis and Related Disorders; holds a patent for Aquaporin-4 sequence that elicits pathogenic T-cell response in animal model of neuromyelitis optica; has consulted for Guidepoint Global, Gerson Lehrman Group, and Cowen Group; received research support from Viropharma/Shire, Acorda, ApoPharma, Sanofi Genzyme, Alnylan, Alexion, Terumo BCT, National Institute of Neurological Disorders and Stroke, and Guthy-Jackson Charitable Foundation. D.M. Wingerchuk is co-editor-in-chief for The Neurologist; is an editorial board member for Current Medical Research and Opinion, Drugs in Context, and Journal of Clinical Apheresis; and received research support from Alexion and TerumoBCT. F. Paul served on the scientific advisory board for Novartis and MedImmune; received speaker honoraria and travel grants from Bayer, Novartis, Biogen Idec, Teva, Sanofi-Aventis/Genzyme, Merck Serono, Alexion, Chugai, MedImmune, and Shire; is an associate editor for Neurology ${ }^{\circledR}$ Neuroimmunology \& Neuroinflammation; is an academic editor for PLoS One; has consulted for Sanofi Genzyme, Biogen Idec, MedImmune, Shire, and Alexion; and received research support from Bayer, Novartis, Biogen Idec, Sanofi-Aventis/Genzyme, Alexion, Merck Serono, German Research Council, Werth Stiftung of the City of Cologne, German Ministry of Education and Research, Arthur Arnstein Stiftung Berlin, EU FP7 Framework Program, Arthur Arnstein Foundation Berlin, GuthyJackson Charitable Foundation, and National Multiple Sclerosis Society of the USA. A.H. Cross served on the scientific advisory board for Roche and Genentech; received travel funding and/or speaker honoraria from Roche, EMD Serono, and AbbVie; served on the editorial board for Brain Pathology and the Journal of Neuroimmunology; was an associate editor for Annals Clinical Translational Neurology; has consulted for Biogen, Sanofi-Aventis/Genzyme, Novartis, Teva Neuroscience, Gerson Lehrman Group, Guidepoint Global, LLC, AbbVie, EMD Serono, Genentech, and Bayer; received honoraria for Projects in Knowledge, Prime Education, Inc., Race to ERASE MS, Conrad N. Hilton Foundation, WebMD; and received research support from Roche, Teva Neuroscience, OBOE, National Institute of Neurological Disorders and Stroke, BarnesJewish Hospital Foundation, and Conrad N. Hilton Foundation. B.G. Weinshenker served on the scientific advisory board for Novartis, Biogen Idec, and Mitsubishi Pharmaceuticals; served as an editorial board member for Canadian Journal of Neurological Sciences, Turkish Journal of Neurology, and Neurology; holds a patent for and receives royalties from NMO-IgG for diagnosis of neuromyelitis optica; is an adjudication committee member for MedImmune Pharmaceuticals and Alexion Pharmaceuticals; and received research support from the Guthy-Jackson Charitable Foundation. A. Jacobs served on the scientific advisory board for Shire Pharmaceuticals; received speaker honoraria from Biogen Idec and Shire Terumo BCT; has consulted for Shire Pharmaceuticals; and received research support from Alexion Pharmaceuticals, NHS, and University of Liverpool. E.C. Klawiter received consulting fees from Acorda Therapeutics, Atlas5D, Biogen Idec, EMD Serono, Genentech, and Shire; and received research support from Atlas5D, Biogen Idec, EMD Serono, Roche, NIH, National MS Society, and Guthy-Jackson Charitable Foundation. T. Chitnis served on the scientific advisory board for Novartis and Genzyme Sanofi; consulted for Biogen Idec, Novartis, Genzyme Sanofi, and Genentech-Roche; and received research support from EMD Serono, Novartis, Biogen, Verily, National Multiple Sclerosis Society, The Peabody Foundation, Consortium for MS Centers, and Guthy-Jackson Charitable Foundation. Go to Neurology.org/nn for full disclosure forms.

Received November 29, 2016. Accepted in final form January 26, 2017.

\section{REFERENCES}

1. Jarius S, Ruprecht K, Wildemann B, et al. Contrasting disease patterns in seropositive and seronegative neuromyelitis optica: a multicentre study of 175 patients. J Neuroinflammation 2012;9:14.

2. Pandit L, Asgari N, Apiwattanakul M, et al. Demographic and clinical features of neuromyelitis optica: a review. Mult Scler 2015;21:845-853.

3. Orton SM, Ramagopalan SV, Brocklebank D, et al. Effect of immigration on multiple sclerosis sex ratio in Canada: the Canadian Collaborative Study. J Neurol Neurosurg Psychiatry 2010;81:31-36.

4. Trojano M, Lucchese G, Graziano G, et al. Geographical variations in sex ratio trends over time in multiple sclerosis. PLoS One 2012;7:e48078.

5. Confavreux C, Hutchinson M, Hours MM, CortinovisTourniaire P, Moreau T. Rate of pregnancy-related relapse in multiple sclerosis. Pregnancy in Multiple Sclerosis Group. N Engl J Med 1998;339:285-291.

6. D'Hooghe MB, D'Hooghe T, De Keyser J. Female gender and reproductive factors affecting risk, relapses and progression in multiple sclerosis. Gynecol Obstet Invest 2013;75:73-84.

7. Bove R, Chitnis T. The role of gender and sex hormones in determining the onset and outcome of multiple sclerosis. Mult Scler 2014;20:520-526.

8. Kim W, Kim SH, Nakashima I, et al. Influence of pregnancy on neuromyelitis optica spectrum disorder. Neurology 2012;78:1264-1267.

9. Fragoso YD, Adoni T, Bichuetti DB, et al. Neuromyelitis optica and pregnancy. J Neurol 2013;260:2614-2619.

10. Shimizu Y, Fujihara K, Ohashi T, et al. Pregnancy-related relapse risk factors in women with anti-AQP4 antibody positivity and neuromyelitis optica spectrum disorder. Mult Scler 2016;22:1413-1420.

11. Bourre B, Marignier R, Zephir H, et al. Neuromyelitis optica and pregnancy. Neurology 2012;78:875-879.

12. Wingerchuk DM, Lennon VA, Pittock SJ, Lucchinetti CF, Weinshenker BG. Revised diagnostic criteria for neuromyelitis optica. Neurology 2006;66:1485-1489.

13. Klawiter E, Alvarez E, Elson L, et al. High risk of initial symptom onset post-partum in neuromyelitis optica. Neurology 2013;80:S60.001.

14. Bove R, Healy BC, Musallam A, Glanz BI, De Jager PL, Chitnis T. Exploration of changes in disability after menopause in a longitudinal multiple sclerosis cohort. Mult Scler 2016;22:935-943. 
15. Harlow SD, Gass M, Hall JE, et al. Executive summary of the Stages of Reproductive Aging Workshop + 10: addressing the unfinished agenda of staging reproductive aging. J Clin Endocrinol Metab 2012;97:1159-1168.

16. Horner-Johnson W, Dobbertin K, Andresen EM, Iezzoni LI. Breast and cervical cancer screening disparities associated with disability severity. Womens Health Issues 2014; 24:e147-e153.

17. Bove R, White CC, Fitzgerald KC, et al. Hormone therapy use and physical quality of life in postmenopausal women with multiple sclerosis. Neurology 2016;87:1457-1463.

18. Sloka JS, Pryse-Phillips WE, Stefanelli M. The relation between menarche and the age of first symptoms in a multiple sclerosis cohort. Mult Scler 2006;12:333-339.

19. Lulu S, Graves J, Waubant E. Menarche increases relapse risk in pediatric multiple sclerosis. Mult Scler 2016;22:193-200.

20. Ramagopalan SV, Valdar W, Criscuoli M, et al. Age of puberty and the risk of multiple sclerosis: a population based study. Eur J Neurol 2009;16:342-347.

21. D'hooghe MB, Haentjens P, Nagels G, D'Hooghe T, De Keyser J. Menarche, oral contraceptives, pregnancy and progression of disability in relapsing onset and progressive onset multiple sclerosis. J Neurol 2012;259:855-861.

22. Quek AM, McKeon A, Lennon VA, et al. Effects of age and sex on aquaporin-4 autoimmunity. Arch Neurol 2012;69:1039-1043.
23. Alwan S, Yee IM, Dybalski M, et al. Reproductive decision making after the diagnosis of multiple sclerosis (MS). Mult Scler 2013;19:351-358.

24. Alonso A, Jick SS, Olek MJ, Ascherio A, Jick H, Hernan MA. Recent use of oral contraceptives and the risk of multiple sclerosis. Arch Neurol 2005;62:1362-1365.

25. Holmqvist P, Hammar M, Landtblom AM, Brynhildsen J. Age at onset of multiple sclerosis is correlated to use of combined oral contraceptives and childbirth before diagnosis. Fertil Steril 2010;94:2835-2837.

26. Villard-Mackintosh L, Vessey MP. Oral contraceptives and reproductive factors in multiple sclerosis incidence. Contraception 1993;47:161-168.

27. Hernan MA, Hohol MJ, Olek MJ, Spiegelman D, Ascherio A. Oral contraceptives and the incidence of multiple sclerosis. Neurology 2000;55:848-854.

28. Thorogood M, Hannaford PC. The influence of oral contraceptives on the risk of multiple sclerosis. $\mathrm{Br} \mathrm{J}$ Obstet Gynaecol 1998;105:1296-1299.

29. Hellwig K, Chen LH, Stancyzk FZ, Langer-Gould AM. Oral contraceptives and multiple sclerosis/clinically isolated syndrome susceptibility. PLoS One 2016;11: e0149094.

30. Bove RM, Healy B, Augustine A, Musallam A, Gholipour T, Chitnis T. Effect of gender on late-onset multiple sclerosis. Mult Scler 2012;18:1472-1479. 


\title{
Neurology \\ Neuroimmunology \& Neuroinflammation
}

\author{
Female hormonal exposures and neuromyelitis optica symptom onset in a multicenter \\ study \\ Riley Bove, Liene Elsone, Enrique Alvarez, et al. \\ Neurol Neuroimmunol Neuroinflamm 2017;4; \\ DOI 10.1212/NXI.0000000000000339
}

This information is current as of March 24, 2017

\section{Updated Information \& \\ Services}

References

Citations

Subspecialty Collections

Permissions \& Licensing

Reprints including high resolution figures, can be found at:

http://nn.neurology.org/content/4/3/e339.full.html

This article cites 30 articles, 1 of which you can access for free at: http://nn.neurology.org/content/4/3/e339.full.html\#\#ref-list-1

This article has been cited by 2 HighWire-hosted articles: http://nn.neurology.org/content/4/3/e339.full.html\#\#otherarticles

This article, along with others on similar topics, appears in the following collection(s):

All Demyelinating disease (CNS)

http://nn.neurology.org//cgi/collection/all_demyelinating_disease_cns

Devic's syndrome

http://nn.neurology.org//cgi/collection/devics_syndrome

Information about reproducing this article in parts (figures,tables) or in its entirety can be found online at:

http://nn.neurology.org/misc/about.xhtml\#permissions

Information about ordering reprints can be found online:

http://nn.neurology.org/misc/addir.xhtml\#reprintsus

Neurol Neuroimmunol Neuroinflamm is an official journal of the American Academy of Neurology.

Published since April 2014, it is an open-access, online-only, continuous publication journal. Copyright

Copyright $\odot 2017$ The Author(s). Published by Wolters Kluwer Health, Inc. on behalf of the American

Academy of Neurology. All rights reserved. Online ISSN: 2332-7812.

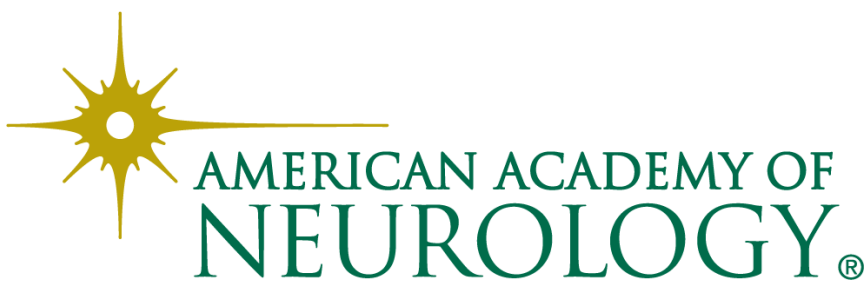

